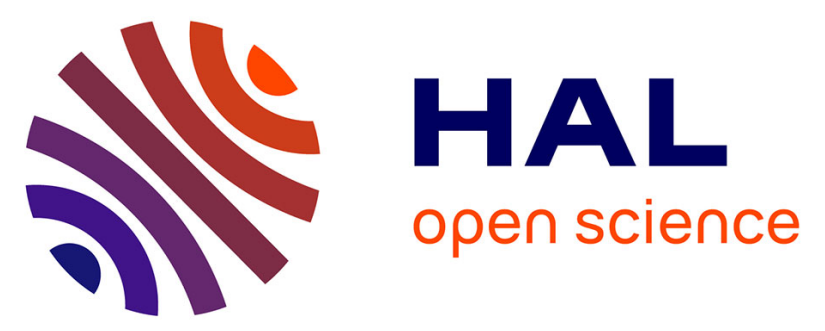

\title{
Rapid cooling of the heart with total liquid ventilation prevents transmural myocardial infarction following prolonged ischemia in rabbits.
}

Mourad Chenoune, Fanny Lidouren, Bijan Ghaleh, Nicolas Couvreur, Jean-Luc Dubois-Rande, Alain Berdeaux, Renaud Tissier

\section{To cite this version:}

Mourad Chenoune, Fanny Lidouren, Bijan Ghaleh, Nicolas Couvreur, Jean-Luc Dubois-Rande, et al.. Rapid cooling of the heart with total liquid ventilation prevents transmural myocardial infarction following prolonged ischemia in rabbits.. Resuscitation, 2010, 81 (3), pp.359-62. 10.1016/j.resuscitation.2009.12.005 . inserm-00472169

\section{HAL Id: inserm-00472169 https://www.hal.inserm.fr/inserm-00472169}

Submitted on 9 Apr 2010

HAL is a multi-disciplinary open access archive for the deposit and dissemination of scientific research documents, whether they are published or not. The documents may come from teaching and research institutions in France or abroad, or from public or private research centers.
L'archive ouverte pluridisciplinaire HAL, est destinée au dépôt et à la diffusion de documents scientifiques de niveau recherche, publiés ou non, émanant des établissements d'enseignement et de recherche français ou étrangers, des laboratoires publics ou privés. 
Rapid cooling of the heart with total liquid ventilation prevents transmural myocardial infarction following prolonged ischemia in rabbits

\author{
Mourad CHENOUNE ${ }^{1,2,3}$, Fanny LIDOUREN ${ }^{1,2,3}$, Bijan GHALEH ${ }^{1,2,3}$, \\ Nicolas COUVREUR ${ }^{1,2,3}$, Jean-Luc DUBOIS-RANDE ${ }^{1,2}$, \\ Alain BERDEAUX ${ }^{1,2,3}$, Renaud TISSIER ${ }^{1,2,3}$
}

${ }^{1}$ INSERM U955, Equipe 3, Créteil, F-94010, France.

${ }^{2}$ Université Paris 12, Faculté de Médecine, Créteil, F-94010, France.

${ }^{3}$ Ecole Nationale Vétérinaire d’Alfort, Maisons-Alfort, F-94704, France.

Submitted as a short paper

Abstract: 250 words

Text: 1802 words

References: 20

Figures/Tables: 2 Figures and 1 Table

Corresponding author: Pr Alain Berdeaux

INSERM U955

Faculté de Médecine Paris 12

8 rue du Général Sarrail

94010 Créteil cedex, France

Tel: +33.1.49.81.36.51 ; Fax: +33.1.48.99.17.77

E-mail: alain.berdeaux@inserm.fr 


\section{Abstract}

Study aim: Total liquid ventilation (TLV) with cooled perfluorocarbons has been demonstrated to induce an ultrafast cardioprotective cooling in rabbits. However, it remains unknown whether this technically challenging strategy would be actually more potent than a conventional external cooling after a prolonged ischemia inducing transmural myocardial infarction. Methods: Anesthetized rabbits were randomly submitted to 60 min of coronary artery occlusion (CAO) under normothermic conditions (Control group, $n=7$ ) or with cooling started at the $5^{\text {th }}$ min of CAO (target left atrial temperature: $32^{\circ} \mathrm{C}$ ). Cooling procedures were either external cooling using cold blankets (EC group, $n=7$ ) or ultrafast cooling initiated by 20-min of TLV (TLV group, $\mathrm{n}=6$ ). An additional group underwent a similar ultrafast cooling protocol started at the $20^{\text {th }}$ min of CAO ( $\mathrm{TLV}_{\text {delayed }}$ group, $\mathrm{n}=6$ ). After reperfusion, all hypothermic animals were rewarmed and infarct size was assessed after 4 h. Results: In the EC group, the target temperature was reached only at 60-min of CAO whereas this timeinterval was dramatically reduced to 15 and 25 min of CAO in TLV and TLV delayed, respectively. Infarct sizes were significantly reduced in TLV and $T L V_{\text {delayed }}$ but not in EC groups as compared to Control $(45 \pm 18 \%, 58 \pm 5 \%, 78 \pm 10 \%$ and $82 \pm 7 \%$ of the risk zone, respectively). Similar significant differences were observed for the sizes of the no-reflow zones $(15 \pm 9 \%, 23 \pm 8 \%, 49 \pm 11 \%$ and $58 \pm 13 \%$ of the risk zone, respectively). Conclusion: Cooling induced by TLV afforded a potent cardioprotection and prevented transmural infarction following prolonged and severe ischemia, even when started later than a surface cooling in rabbits.

\section{Key Words :}

Cardioprotection ; Cooling ; Hypothermia ; Liquid ventilation ; Myocardial infarction; Ischemia. 


\section{Introduction}

Myocardial cooling is known to limit infarct size in animal models of coronary artery occlusion and reperfusion. ${ }^{1,2}$ The maximal myocardial salvage is afforded for a cardiac temperature of $32^{\circ} \mathrm{C}$ without major hemodynamic adverse effect. ${ }^{2}$ To exert an optimal protection, such a target temperature should however be reached very fast after the onset of ischemia to effectively shorten the normothermic ischemic time. ${ }^{1-3}$ Many experimental studies investigating cooling for cardioprotection have been performed with topical cooling using, e.g., bags of iced saline on the epicardium. ${ }^{1}$ This allows a rapid and selective cooling of the heart but this would not be feasible in patients. Other cooling strategies have therefore been experimentally investigated such as closed circuit of pericardioperfusion, ${ }^{4}$ blood extracorporal cooling ${ }^{2}$ or endovascular thermodes. ${ }^{5}$ The latter strategy has been also tried in patients undergoing primary coronary intervention but no infarct size reduction was observed in the overall analyses..$^{6-8}$ One might speculate that this negative result was related to an insufficient rate of cooling.

More recently, total liquid ventilation (TLV) with temperature controlledperfluorocarbons has been proposed to induce ultra-fast cardioprotective cooling in the experimental setting. ${ }^{3}$ Our group demonstrated that this strategy decreases myocardial temperature within 5 to $10 \mathrm{~min}$ and potently protects the heart against infarction and subsequent dysfunction in rabbits. ${ }^{3,9}$ These data were obtained using an experimental model in which a non transmural infarction ( $50 \%$ of the risk zone in normothermic conditions) was obtained with 30-min of coronary artery occlusion followed by reperfusion. One could however argue that to further demonstrate the relevance of this technically challenging strategy, it would be critical to determine whether TLV is actually more protective than a simpler and conventional external cooling using cold blankets. ${ }^{7}$ To better predict the potential 
clinical benefit, we also need to determine whether TLV is still protective with prolonged durations of ischemia which will induce transmural myocardial infarction in normothermic conditions (e.g., 60-min in anesthetized rabbits). Another important aspect is to investigate whether TLV can also reduce the extent of the no-reflow size which predicts subsequent remodelling and outcome. ${ }^{10}$ Accordingly, the goal of the present study was to compare the effects of cooling induced by TLV vs external cooling on myocardial infarct and no-reflow sizes following a prolonged 60-min ischemia in rabbits. 


\section{Methods}

The animal instrumentation and the ensuing experiments were conducted in accordance with French official regulations after approval by the local ethical committee.

\section{Animal surgery}

New Zealand rabbits $(2.5-3.0 \mathrm{~kg})$ were anesthetized using zolazepam, tiletamine and pentobarbital (all 20-30 mg/kg i.v.). The animals were intubated, mechanically ventilated and a left thoracotomy was performed. A thermal probe was implanted within the left atrium and a suture was passed beneath a major branch of the left coronary artery. The ends of the ligature were passed through a short propylene tubing to form a snare. A coronary artery occlusion (CAO) was induced during 60-min by pulling the snare through the tubing. Reperfusion was subsequently induced by releasing the snare. The chest was then closed in layers.

\section{Experimental protocol}

All rabbits were submitted to 60-min of CAO and 4-h of reperfusion. As shown in Figure 1 (upper panel), they randomly underwent either a normothermic CAO (Control group) or cooling from the $5^{\text {th }}$ min to the end of CAO (target left atrial temperature: $32^{\circ} \mathrm{C}$ ). Cooling procedures were either external cooling using cold blankets (EC group) or ultrafast cooling initiated by 20-min of total liquid ventilation (TLV group). An additional group underwent a similar ultrafast cooling started at the $20^{\text {th }}$ min of CAO ( $T L V_{\text {delayed }}$ group). After the onset of reperfusion, all hypothermic animals were rewarmed using infra-red lights and thermal pads. Throughout the protocol, arterial blood pressure and heart rate were monitored from a catheter implanted in the ear artery and from the electrocardiogram, respectively. Left atrial temperature was also recorded. 
In $T L V$ and $T_{L V}$ delayed groups, rabbits were switched to liquid ventilation by filling the lung with perfluorocarbon and then connecting the endotracheal tube to the liquid ventilator. The perfluorocarbon was a mixture of perfluorobutyltetrahydrofurane and perfluoropropyltetrahydropyrane (RM101, Miteni, Milano, Italy). The ventilator was set to a tidal volume of $10-15 \mathrm{ml} / \mathrm{kg}$ body weight with 6 breaths/min. The perfluorocarbon mixture was bubbled with $100 \% \mathrm{O}_{2}$. This protocol has previously been demonstrated to maintain normal blood gases. ${ }^{3,9}$ The temperature of the heat exchanger was adjusted to maintain the left atrial temperature at $\sim 32^{\circ} \mathrm{C}$.

\section{Measurement of risk area, infarct size an no-reflow zones}

After completion of reperfusion, the chest was reopened and thioflavine S (4\%; 1.5 $\mathrm{ml} / \mathrm{kg}$ ) was rapidly infused through the left atrium. Rabbits were then sacrificed using pentobarbital followed by potassium chloride. After excision, the hearts were perfused retrogradely with Alcian blue (0.5\%) and cut into slices. The risk zone was identified as the non-blue region. Slices were photographed using UV light to identify the region of no-reflow as the dark zone. They were then incubated in 1\% triphenyltetrazolium chloride, fixed in formaldehyde and rephotographed. Infarcted area was identified as the TTC-unstained tissue. The areas of no-reflow, infarct and risk zone were blindly determined from the pictures by a single observer using planimetry (Figure 2C).

\section{Statistical analysis}

Values are expressed as means \pm SD. Hemodynamic parameters were compared using a two-way ANOVA for repeated measures. This was performed at 6 time points at baseline, during CAO (at $15^{\text {th }}, 30^{\text {th }}$ and $60^{\text {th }}$ min) and reperfusion (at $1^{\text {st }}$ and $4^{\text {th }} \mathrm{h}$ ), with pairwise comparisons to the Control group at each time-point using a Student $t$-test and Bonferroni 
correction. Temperatures were also compared between hypothermic vs Control groups using a one-way ANOVA at baseline and a two-way ANOVA for repeated measures during CAO and reperfusion. As numerous time-points were used for this last analysis (i.e., 8 during CAO and 7 during reperfusion), we did not perform pairwise comparison at each time-point in order to avoid multiple comparisons. Risk zone (\% left ventricle) were compared between groups using a one-way ANOVA followed by Student $t$-tests with Bonferonni Correction. No reflow and infarct sizes (\% left ventricle) were compared using an ANCOVA with risk zone size as covariate. Significant differences were determined as $\mathrm{p}<0.05$. 


\section{Results}

Thirty rabbits were initially included in the present study (10, 8, 6 and 6 in the Control, EC, TLV and TLV $V_{\text {delayed }}$ groups, respectively). Three and one animals died from ventricular fibrillation in the Control and EC group, respectively. Finally, twenty-six rabbits successfully underwent the complete protocol, i.e., 7, 7, 6 and 6 in Control, EC, TLV and TLV $_{\text {delayed }}$ groups, respectively.

As illustrated in Figure 1 (lower panel), left atrial temperatures were not significantly different among groups at baseline. In the EC group, the left atrial target temperature of $32^{\circ} \mathrm{C}$ was reached only at 60 -min of CAO whereas this time-interval was dramatically reduced to 15 and 25-min of CAO in TLV and $\mathrm{TLV}_{\text {delayed, }}$ respectively (Figure 1). After the onset of reperfusion and warm-up initiation, all hypothermic animals similarly recovered normothermic values within two hours.

As shown in Table I, heart rate and mean arterial pressure were not significantly different among groups at baseline. Mean arterial pressure was also not significantly different between groups throughout the experimental protocol. Conversely, as soon as hypothermia was induced in EC, TLV and TLV $\mathrm{V}_{\text {delayed }}$ groups, heart rate significantly decreased by $-20 \%$ to $-34 \%$ as compared to the normothermic Control values.

Risk zones were not significantly different among Control, EC, TLV and TLV delayed groups (37 $\pm 5 \%, 39 \pm 7 \%, 38 \pm 8 \%, 39 \pm 9 \%$ of the left ventricle, respectively). As shown in Figure 2, infarct and no-reflow sizes were significantly decreased in TLV and TLV delayed but not in EC as compared to Control. 


\section{Discussion}

The present study demonstrates that rapid cooling of the ischemic heart with TLV reduced infarct and no-reflow sizes after a 60-min coronary artery occlusion in rabbits. Importantly, this duration of ischemia induced a sub-maximal and transmural myocardial infarction in normothermic rabbits, with virtually no myocardial salvage by reperfusion. This result demonstrates that the protective effect of ultrafast cooling of the heart is not limited by any ceiling of cardioprotection following prolonged ischemia, as opposed to almost all the other well known cardioprotective approaches which lose their effect with increasing durations of ischemia. ${ }^{11-13}$ This was further confirmed by the powerful protection against noreflow. ${ }^{10}$

Interestingly, external cooling started early during ischemia was able to reach hypothermic levels at the end of CAO but this was not able to afford any significant cardioprotection. This suggests that hypothermia limited to the beginning of the reperfusion time is not protective, as previously described. ${ }^{1-3,14}$ In contrast, cooling with TLV was so protective that it was still protective even started at the $20^{\text {th }}$ of ischemia. This further emphasizes that a cooling strategy must be designed to decrease the cardiac temperature as fast as possible to effectively shorten the normothermic period of ischemia. One would argue however that a longer duration at target temperature in the EC group could have led to different results. Target temperature was indeed reached only at the end of the 60-min CAO and rewarming was immediately started, concomitantly with reperfusion. We speculate however that this did not impact our results as hypothermia during only reperfusion failed to reduce infarct size in most experimental reports. ${ }^{1-3,14}$ We should also emphasize that we induced a fast rewarming in comparison to the clinical recommendations. This fast rewarming 
can be considered as a limitation but this was used in order to recover normothermic values at the end of the protocol.

The present study further supports the clinical relevance of rapid cooling by liquid ventilation, as previously suggested. ${ }^{9,15,16}$ This would be of importance as several prototypes of total liquid ventilators have been developed and may be used in adults after technical improvements. ${ }^{17,}{ }^{18}$ By the present time, no clinical reports have properly investigated cooling using TLV in humans but several studies have tested other cooling strategies such as external or endovascular cooling. The first large scale clinical trial implementing cooling in the treatment of myocardial infarction was done using endovascular cooling devices in the COOL-MI and ICE-IT-1 studies. ${ }^{6-8}$ In both studies, there was no overall benefit regarding infarct size with cooling, probably according to insufficient cooling rate. Ultra-fast cooling with TLV would therefore afford a greater protection even if technically challenging. It would be even more relevant to protect the heart against myocardial infarction in patients resuscitated from cardiac arrest with underlying coronary disease. ${ }^{7}$ In this setting, one might predict that TLV would protect both the heart and the brain and would be less challenging than for the treatment of myocardial infarction. Recently, it was also importantly demonstrated that intra-arrest hypothermia induced by liquid ventilation facilitates resumption of spontaneous circulation in a swine cardiac arrest model. ${ }^{19,20}$

In conclusion, the present study demonstrates that rapid cooling induced by TLV affords cardioprotection against prolonged and severe ischemia in rabbits, even when started later than a low rate surface cooling. This result also supports the need for further investigations of TLV in the resuscitation setting. 


\section{Conflict of Interest}

No disclosure. 


\section{Acknowledgements}

This work was supported by grants “TLVenCool 06-JCJC-0078” from the French “Agence Nationale pour la Recherche” and ET7-460 from the Fondation de l'Avenir. The authors are greatly indebted to Dr J.M. Downey, M.V Cohen and J.C. Parker for their insightful comments and creative ideas at various stages of our research. Dr Chenoune was supported by grants from the "Groupe de Réflexion sur la Recherche Cardiovasculaire” and by a “Poste d’accueil - INSERM 2009”. 


\section{References}

1. Hale SL, Dave RH, Kloner RA. Regional hypothermia reduces myocardial necrosis even when instituted after the onset of ischemia. Basic Res Cardiol 1997;92:351-7.

2. Miki T, Liu GS, Cohen MV, Downey JM. Mild hypothermia reduces infarct size in the beating rabbit heart: a practical intervention for acute myocardial infarction? Basic Res Cardiol 1998;93:372-83.

3. Tissier R, Hamanaka K, Kuno A, Parker JC, Cohen MV, Downey JM. Total liquid ventilation provides ultra-fast cardioprotective cooling. J Am Coll Cardiol 2007;49:601-5.

4. Dave RH, Hale SL, Kloner RA. Hypothermic, closed circuit pericardioperfusion: a potential cardioprotective technique in acute regional ischemia. $\mathrm{J}$ Am Coll Cardiol 1998;31:1667-71.

5. Dae MW, Gao DW, Sessler DI, Chair K, Stillson CA. Effect of endovascular cooling on myocardial temperature, infarct size, and cardiac output in human-sized pigs. Am J Physiol 2002;282:H1584-91.

6. O’Neill WW for the COOL-MI study group. A prospective randomized trial of mild systemic hypothermia during PCI treatment of ST elevation myocardial infarction. 15th Annual Transcatheter Cardiovascular Therapeutics, 2003.

7. Holzer M, Behringer W. Therapeutic hypothermia after cardiac arrest and myocardial infarction. Best Pract Res Clin Anaesthesiol 2008;22:711-28.

8. Grines CL for the ICE-IT study group. Intravascular cooling adjunctive to percutaneous coronary intervention for acute myocardial infarction. 16th Annual Transcatheter Cardiovascular Therapeutics, 2004.

9. Tissier R, Couvreur N, Ghaleh B, Bruneval P, Lidouren F, Morin D, Zini R, Bize A, Chenoune M, Belair MF, Mandet C, Douheret M, Dubois-Rande JL, Parker JC, Cohen MV, 
Downey JM, Berdeaux A. Rapid cooling preserves the ischaemic myocardium against mitochondrial damage and left ventricular dysfunction. Cardiovasc Res 2009;83:345-53.

10. Reffelmann T, Kloner RA. The no-reflow phenomenon: A basic mechanism of myocardial ischemia and reperfusion. Basic Res Cardiol 2006;101:359-72.

11. Gumina RJ, Buerger E, Eickmeier C, Moore J, Daemmgen J, Gross GJ. Inhibition of the $\mathrm{Na}^{+} / \mathrm{H}^{+}$exchanger confers greater cardioprotection against 90 minutes of myocardial ischemia than ischemic preconditioning in dogs. Circulation 1999;100:2519-26.

12. Tissier R, Aouam K, Berdeaux A, Ghaleh B. Evidence for a ceiling of cardioprotection with a nitric oxide donor-induced delayed preconditioning in rabbits. J Pharmacol Exp Ther 2003;306:528-31.

13. Couvreur N, Tissier R, Pons S, Chenoune M, Waintraub X, Berdeaux A, Ghaleh B. The ceiling effect of pharmacological postconditioning with the phytoestrogen genistein is reversed by the GSK3b inhibitor SB 216763 [3-(2,4-dichlorophenyl)-4(1-methyl-1H-indol-3yl)-1H-pyrrole-2,5-dione] through mitochondrial ATP-dependent potassium channel opening. J Pharmacol Exp Ther 2009;329:1134-41.

14. Maeng M, Mortensen UM, Kristensen J, Kristiansen SB, Andersen HR. Hypothermia during reperfusion does not reduce myocardial infarct size in pigs. Basic Res Cardiol 2006;101:61-8.

15. Yang SS, Jeng MJ, McShane R, Chen CY, Wolfson MR, Shaffer TH. Cold perfluorochemical-induced hypothermia protects lung integrity in normal rabbits. Biol Neonate 2005;87:60-5.

16. Lew WYW. A cool heart protected from infarction: clinical translation of breathing chilled liquids. J Am Coll Cardiol 2007;49:606-7.

17. Robert R, Micheau P, Cyr S, Lesur O, Praud JP, Walti H. A prototype of volumecontrolled tidal liquid ventilator using independent piston pumps. Asaio J 2006;52:638-45. 
18. Tredici S, Komori E, Funakubo A, Brant DO, Bull JL, Bartlett RH, Hirschl RB. A prototype of a liquid ventilator using a novel hollow-fiber oxygenator in a rabbit model. Crit Care Med 2004;32:2104-9.

19. Riter HG, Brooks LA, Pretorius AM, Ackermann LW, Kerber RE. Intra-arrest hypothermia: both cold liquid ventilation with perfluorocarbons and cold intravenous saline rapidly achieve hypothermia, but only cold liquid ventilation improves resumption of spontaneous circulation. Resuscitation 2009;80:561-6.

20. Staffey KS, Dendi R, Brooks LA, Pretorius AM, Ackermann LW, Zamba KD, Dickson E, Kerber RE. Liquid ventilation with perfluorocarbons facilitates resumption of spontaneous circulation in a swine cardiac arrest model. Resuscitation 2008;78:77-84. 


\section{Legends of figures}

\section{Figure 1}

Experimental protocol (upper panel) and left atrial temperature recording throughout the protocol (lower panel)

CAO, coronary artery occlusion; CAR, coronary artery reperfusion; EC, external cooling using ice-filled cold blankets from the $5^{\text {th }}$ min of CAO to the end of CAO; TLV, cooling instituted by a 20 min episode of total liquid ventilation initiated at the $5^{\text {th }}$ min of CAO; $T L V_{\text {delayed, }}$ cooling instituted by a 20 min episode of total liquid ventilation initiated at the $20^{\text {th }}$ min of CAO. * $p<0.05$ vs Control throughout the protocol using a two-way ANOVA for repeated-measures with 8 time points during CAO and 6 during reperfusion, respectively. Pairwise comparisons at each time-point were not performed in order to avoid multiple comparisons.

\section{Figure 2}

Panel A and B: Infarct and no-reflow sizes expressed as percentage of the risk zone in the different groups of rabbits. Open circles represent individual infarct sizes and closed circles represent the mean $\pm \mathrm{SD}$ of the corresponding group.

Panel C: Photographs of representative left ventricle slices of a rabbit in each group. Under halogen light (left column), areas lacking blue dye show the risk zone. Within this zone, the territories that were stained in red by triphenyltetrazolium chloride are salvaged. In contrast the gray territories are infarcted. Under UV light (right column), the myocardium that recovered perfusion after the ischemic episode is fluorescent and the areas of no-reflow are dark.

See legend of Figure 1; * $p<0.05$ vs Control and EC. 


\section{Table I}

Heart rate and mean arterial pressure during the experimental protocol

\begin{tabular}{|c|c|c|c|c|c|c|}
\hline \multirow{2}{*}{ Groups } & \multirow{2}{*}{ Baseline } & \multicolumn{3}{|c|}{ Coronary artery occlusion } & \multicolumn{2}{|c|}{ Reperfusion } \\
\hline & & $15 \min$ & $30 \mathrm{~min}$ & $60 \mathrm{~min}$ & $1 \mathrm{~h}$ & $4 \mathrm{~h}$ \\
\hline \multicolumn{7}{|c|}{ Heart rate (beats/min) } \\
\hline Control & $240 \pm 23$ & $236 \pm 17$ & $236 \pm 21$ & $216 \pm 16$ & $235 \pm 18$ & $230 \pm 33$ \\
\hline $\mathrm{EC}$ & $251 \pm 35$ & $233 \pm 30$ & $214 \pm 34$ & $180 \pm 23 *$ & $223 \pm 37$ & $252 \pm 28$ \\
\hline TLV & $244 \pm 23$ & $159 \pm 19 *$ & $161 \pm 18^{*}$ & $173 \pm 20 *$ & $225 \pm 26$ & $239 \pm 17$ \\
\hline $\mathrm{TLV}_{\text {delayed }}$ & $248 \pm 26$ & $242 \pm 21$ & $156 \pm 15^{*}$ & $160 \pm 18 *$ & $206 \pm 40$ & $229 \pm 29$ \\
\hline \multicolumn{7}{|c|}{ Mean arterial pressure $(\mathrm{mmHg})$} \\
\hline Control & $63 \pm 8$ & $65 \pm 10$ & $68 \pm 11$ & $57 \pm 14$ & $62 \pm 14$ & $58 \pm 6$ \\
\hline EC & $66 \pm 8$ & $64 \pm 6$ & $61 \pm 6$ & $63 \pm 9$ & $59 \pm 6$ & $60 \pm 8$ \\
\hline TLV & $67 \pm 9$ & $60 \pm 2$ & $58 \pm 8$ & $58 \pm 10$ & $59 \pm 16$ & $57 \pm 9$ \\
\hline $\mathrm{TLV}_{\text {delayed }}$ & $68 \pm 10$ & $71 \pm 4$ & $61 \pm 9$ & $64 \pm 12$ & $66 \pm 6$ & $58 \pm 4$ \\
\hline
\end{tabular}

CAO, coronary artery occlusion; EC, external cooling using ice-filled cold blankets from the $5^{\text {th }}$ min of CAO to the end of CAO; TLV, cooling instituted by a 20 min episode of total liquid

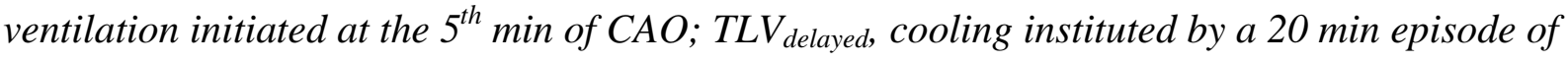
total liquid ventilation initiated at the $20^{\text {th }}$ min of CAO. ${ }^{*} p<0.05$ vs corresponding Control value. 
FIGURE 1

CAR 4h

Control

EC

TLV

$T L V_{\text {delayed }}$

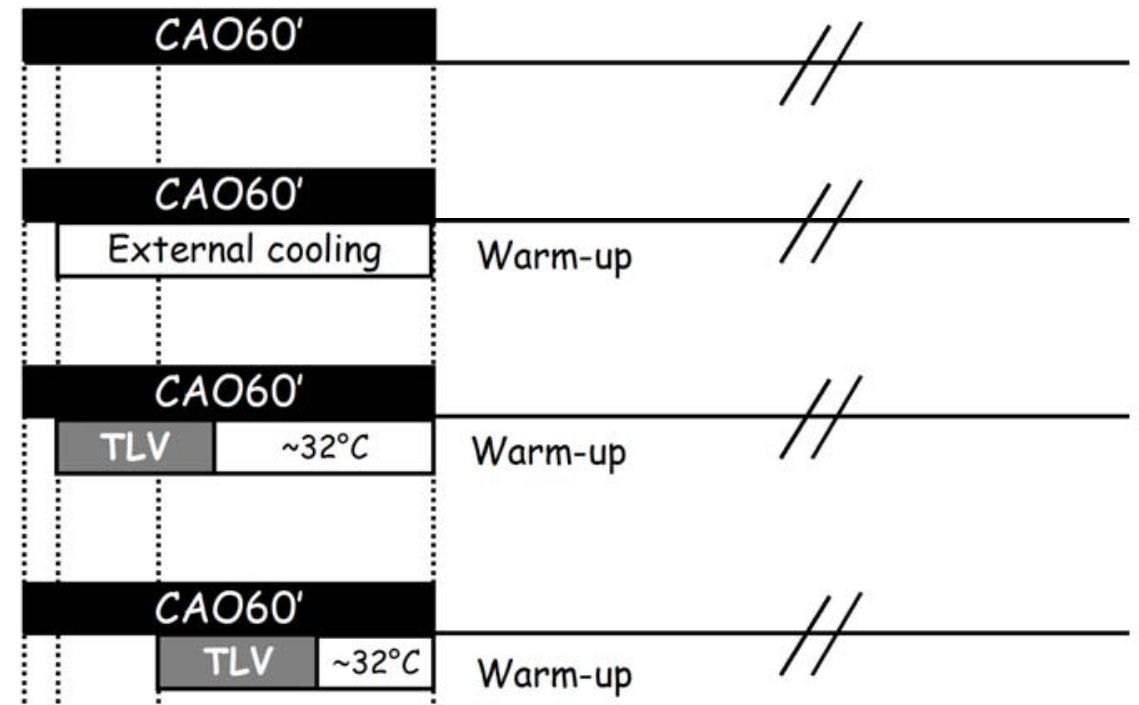

ত 40.0

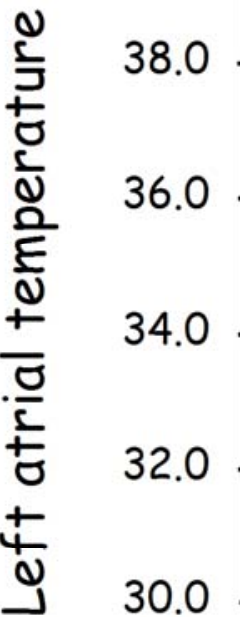

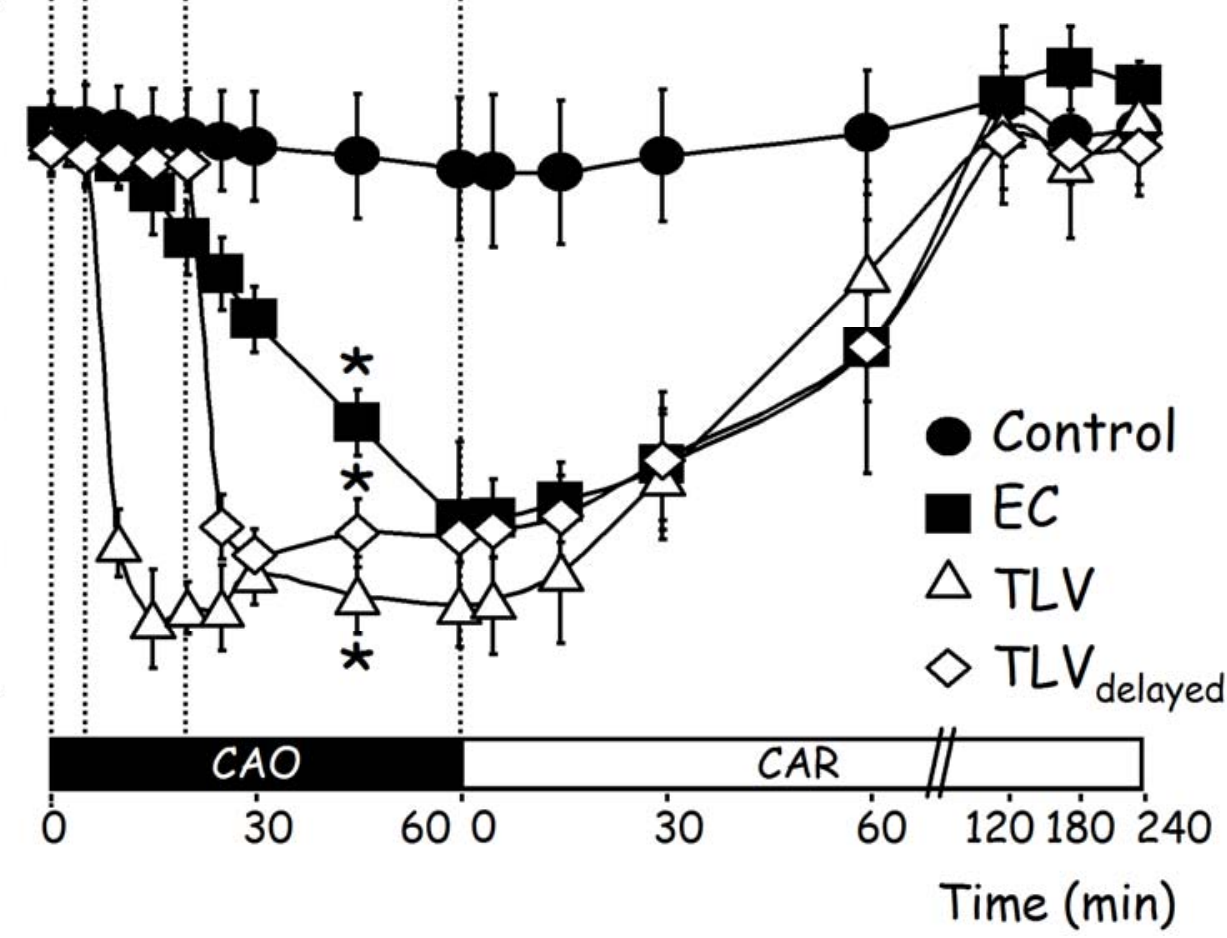


FIGURE 2
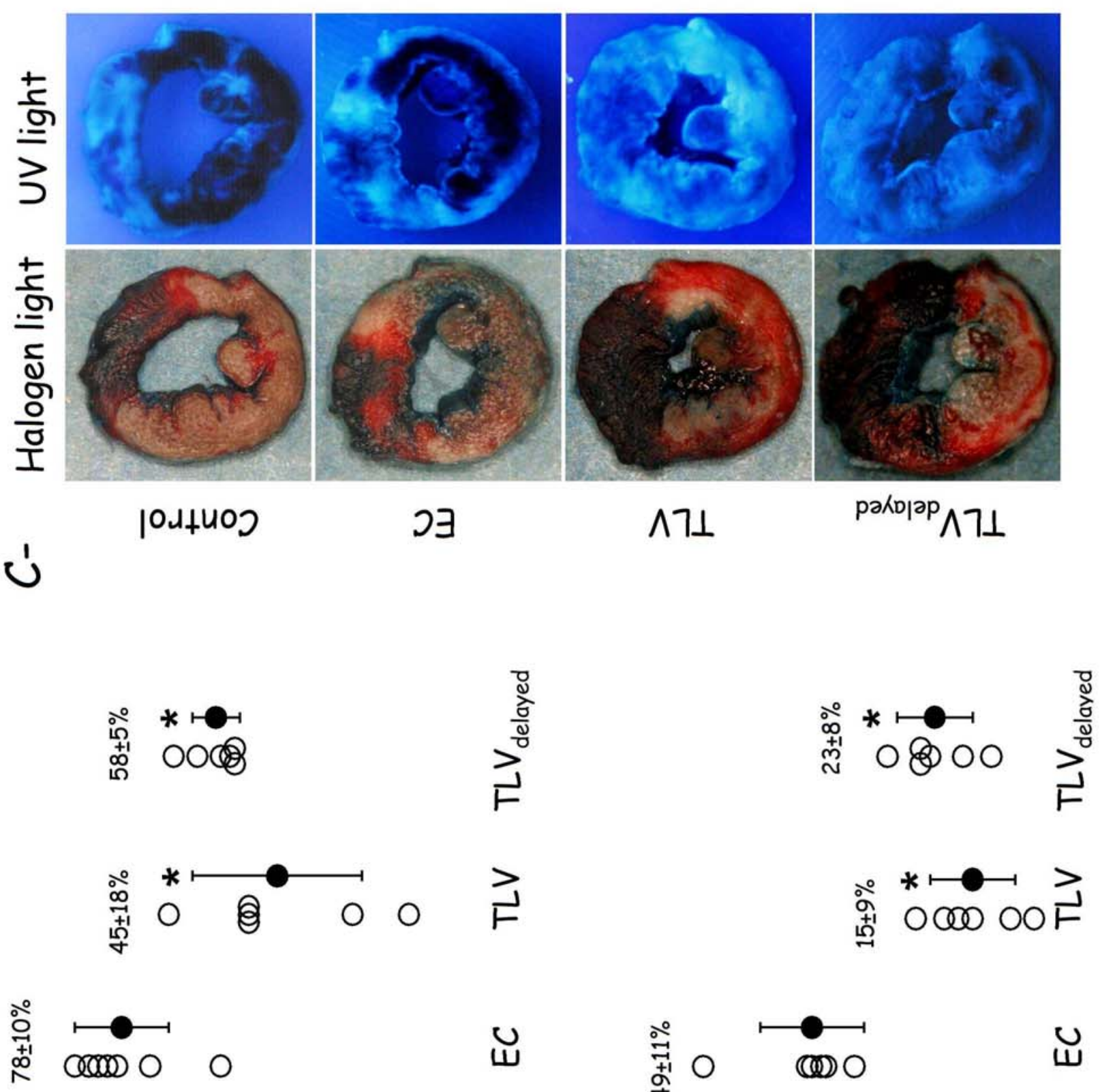

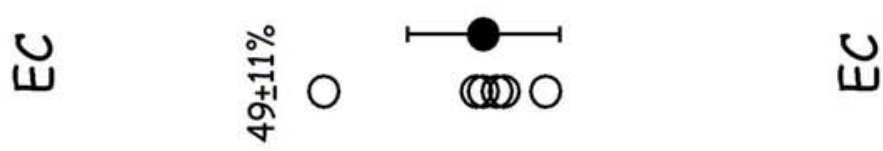
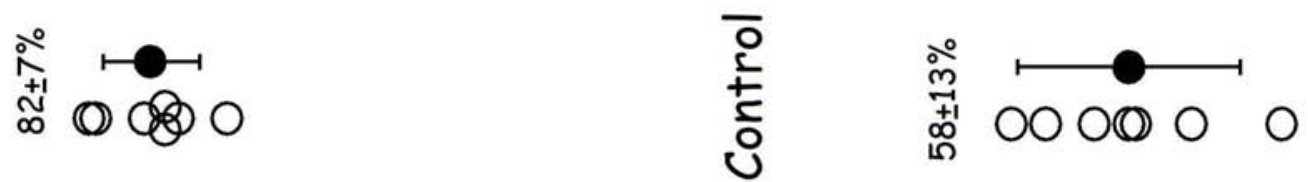

$\overline{0}$
¿̇
¿
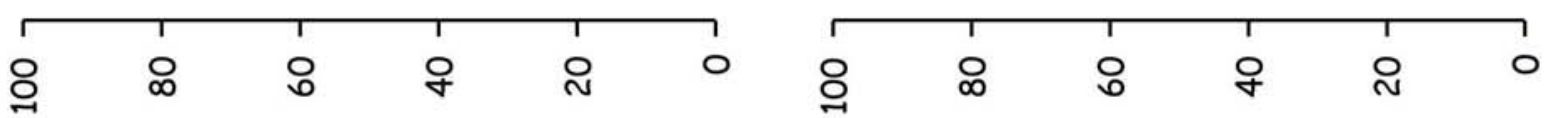

(auoz ys! $\%$ ) az!s +JuDfuI $<$

(auoz ys!a \%) MO|fad ON ஸ́ 